\title{
Credibilidade em jogo: 0 uso do fact-checking no portal G1 e a checagem colaborativa nas Organizações Globo
}

\section{Marta Thaís Alencar Cosme}

Universidade Federal do Piauí, Teresina, PI, Brasil

ORCID: http://orcid.org/0000-0003-0034-4703

\section{Jacqueline Lima Dourado}

Universidade Federal do Piauí, Teresina, PI, Brasil

ORCID: http://orcid.org/0000-0002-5546-0720

\section{Resumo}

O presente artigo analisa a checagem colaborativa do Fato ou Fake, serviço de monitoramento e checagem de conteúdos do Grupo Globo. Para tanto, o trabalho realiza um estudo de caso a partir das diretrizes contidas no Plano Editorial do Grupo e na seção Fato ou Fake do Portal G1, que pontuam o fact-checking como estratégia de credibilidade.

\section{Palavras-chave}

Jornalismo; Fact-checking; Economia Política da Comunicação

\section{Introdução}

A apuração é uma prática tradicional da profissão jornalística. E na internet, a apuração vem encontrando novas oportunidades assim como obstáculos e desafios. Um desses obstáculos é o excesso de desinformações. Há uma "obesidade" informativa na internet e nas redes sociais.

De acordo com o Trust Barometer, $20^{\mathrm{a}}$ pesquisa anual de confiança e credibilidade da Edelman Intelligence (consultoria global de análise de instituições), as pessoas confiam nas organizações com base em dois atributos distintos: competência e comportamento ético (EDELMAN, 2020). 0 Trust Barometer lançado em janeiro de 2020 revela que nenhuma das quatro instituições - governo, empresas, ONGs e mídia - são vistas como confiáveis. As empresas são classificadas com maior competência (64\%). As ONGs lideram o 
comportamento ético em relação ao governo (uma diferença de 31 pontos) e às empresas (uma diferença de 25 pontos). Governo e mídia são vistos como incompetentes e antiéticos (EDELMAN, 2020).

Empresas de jornalismo no mundo vêm mesclando novas e velhas ferramentas de apuração para garantir a credibilidade de suas notícias. Um desses recursos é o factchecking (verificação de fatos). Apesar das semelhanças com o conceito de apuração, o factchecking é uma prática diferente do procedimento de apuração das redações jornalísticas tradicionais, pois é uma atividade que tenta fazer o que mais incomoda o jornalismo convencional: avaliar e, muitas vezes, contradizer as contas oficiais. E não se baseia apenas em declarações das fontes, mas sim em investigar os dados declarados (GRAVES, 2013).

Neste cenário de descrédito com a mídia tradicional, as ferramentas de fact-checking têm uma importância maior já que reposiciona o jornalismo no ecossistema de informação dominado pelas plataformas (SEIBT, 2019) e estabelece novos parâmetros de transparência que desconstroem a notícia na sua forma convencional, oferecendo maior credibilidade ao papel do jornalista.

Embora pareça que o fact-checking surgiu na internet, o gênero na verdade iniciou na televisão. A prática foi iniciada em 1991, durante a eleição presidencial nos Estados Unidos. Na época, o jornalista norte-americano Brooks Jackson, que atuava no canal americano de televisão por assinatura CNN, decidiu verificar as promessas e declarações dos presidenciáveis, juntamente com uma equipe do veículo.

Após o trabalho encerrado na CNN, o jornalista decidiu em 2003 criar o FactCheck.org, primeiro veículo especializado em fact-checking do mundo. 0 projeto também conta com a ajuda da Universidade da Pensilvânia e do Annenberg Public Policy Center. Em seguida, foi a vez do jornalista norte-americano Bill Adair, que fundou o PolitiFact (projeto de fact-checking sem fins lucrativos operado pelo Instituto Poynter em São Petersburgo, Flórida).

A prática vem se espalhando pelo mundo com maior notoriedade a partir de 2014 . Atualmente, existem 341 projetos ativos de verificação de fatos, 51 acima do relatório de junho de 2020 do Duke University Reporters' Lab (STENCEL; LUTHER, 2021). No Brasil, a Folha foi um dos primeiros veículos de comunicação a adotar blogs de checagem¹

\footnotetext{
${ }^{1}$ Para Palacios (2019), a introdução da função de ombudsman nas redações constituiu importante inovação nos mecanismos de fact-checking. No Brasil, a Folha de S. Paulo também foi o primeiro veículo a criar o cargo de ombudsman em 1989.
} 
Nas eleições de 2010, a Folha promoveu dois blogs para apurar a veracidade das declarações dos candidatos à Presidência da República. Um deles foi o Mentirômetro, que classificava as falas dos candidatos em: Não é bem assim; Aumentou e distorceu; Mentiu e Verdade. 0 outro foi o Promessômetro, que analisava as promessas dos candidatos, principalmente se elas tinham chances de serem concretizadas.

Em 2002, o analista de sistemas Gilmar Lopes lançou o site E-farsas com o intuito de desmitificar histórias falsas na internet. Em anos posteriores surgiram outras iniciativas: Lupa $^{2}$ (2015), Aos Fatos ${ }^{3}$ (2015) e Boatos ${ }^{4}$ (2013). Mas além dessas iniciativas surgiram no país projetos colaborativos inspirados no Crosscheck ${ }^{5}$ lançado na França em 2017.

$\mathrm{Na}$ época, 37 veículos da imprensa francesa se reuniram para lançar o projeto CrossCheck, que contou com patrocínio do Google. 0 projeto representou uma coalização entre veículos como os jornais Le Monde e Libération, canais de TV aberta da rede France Télévisions, sites de notícia e entidades do segmento acadêmico. Além disso, o projeto reuniu cerca de 250 jornalistas de diversos veículos.

Inspirado pelo CrossCheck francês, o Projeto Comprova foi criado no período eleitoral de 2018, onde reuniu jornalistas de 24 diferentes veículos: Agence France-Presse, TV Band, Rádio Bandeirantes, Band News, Correio do Povo, Revista Exame, Folha de S.Paulo, TV Futura, Site GaúchaZH, Gazeta Online, Metro Jornal, Nexo Jornal, Nova Escola, NSC Comunicação, Estadão, O Povo, Revista Piauí, Poder 360, Rádio Band News FM, SBT, Jornal do Commercio, Veja e Uol.

Cada veículo que participou do Comprova ${ }^{6}$ nas eleições de 2018 designou profissionais para detectar fake news. Ao final do período eleitoral, o Comprova informou que publicou 146 histórias para desmentir ou confirmar informações. Em publicação intitulada "Até logo", datada de 30 de outubro de 2018, o projeto informou que encerraria suas atividades de verificação. Mas em junho de 2019, o Comprova lançou sua segunda fase do projeto (COMPROVA, 2019).

Seguindo as diretrizes dessas iniciativas, grandes conglomerados da mídia tradicional estão investindo em fact-checking e em checagem colaborativa em suas redações e contando com equipes de profissionais de diferentes perfis, treinamentos e habilidades. 0

\footnotetext{
${ }^{2}$ A autonomeada primeira agência de fact-checking do país tem um site hospedado no portal da Revista Piauí.

3 É uma organização sem fins lucrativos de fact-checking,

${ }^{4} \mathrm{O}$ site é coordenado por uma equipe de jornalistas.

50 CrossCheck foi idealizado pelo First Draft News, uma ONG fundada em 2015, que reuniu 37 redações francesas e britânicas para verificar informações em conjunto na internet durante a última campanha presidencial francesa.

${ }^{6}$ Em junho de 2021, o Projeto Comprova iniciou sua quarta fase com 33 veículos de comunicação.
} 
G1 (Portal de notícias do Globo) criado às vésperas das eleições de 2006 passou por muitas mudanças desde o seu lançamento. Dentre elas, o portal divulgou em 23 de março de 2017 uma editoria exclusiva de fact-checking chamada É ou Não É, que apurava declarações de políticos e outras personalidades públicas, classificando-as em verdadeiras ou falsas.

Em 30 de julho de 2018, a editoria mudou de título e passou a se chamar de "Fato ou Fake". Desde então, o portal G1 faz apuração colaborativa (Crosscheck) com outras equipes do Grupo Globo: O Globo, Extra, Época, Valor, CBN, GloboNews e TV Globo. Cada um desses veículos pode publicar em seus respectivos canais, após as checagens feitas em conjunto. Atualmente, o Grupo Globo reconhece o "Fato ou Fake" como um serviço de monitoramento e checagem de conteúdos de todos os veículos que integram a organização.

Desde o fim do século passado, as organizações noticiosas e jornalistas têm sido desafiados a adaptar suas práticas. 0 modelo de empresa jornalística do século XXI está estremecido. "Mas as mudanças não se limitam ao negócio, incidem também sobre as características do texto jornalístico e os processos de sua produção, bem como sobre o jornalista e seu reconhecimento social." (SEIBT, 2019, p. 24).

O livre compartilhamento de dados aumentou a concorrência entre plataformas e organizações da mídia para conquistar a atenção e preferência dos usuários na internet. "Fica muito difícil diferenciar notícia de propaganda no newsfeed do Facebook, mesmo porque sites noticiosos também se viram impelidos nos últimos anos a publicar conteúdos mais 'viralizáveis' para mobilizar audiência e ampliar lucros com publicidade digital." (SEIBT, 2019, p. 30).

Ureta (2016) identifica que os modelos de jornalismo consolidados durante o século passado estão hoje em questão e sujeitos a intensos processos de mudança que fazem com que o jornalismo viva um momento de incerteza. Assim, algumas empresas têm visto a crise nos negócios (perda de anunciantes e assinaturas) como uma oportunidade para se reinventarem e otimizarem procedimentos e custos sem comprometer a qualidade do produto final.

Diante disso, a presente pesquisa destaca que uso do fact-checking é uma estratégia de checagem colaborativa nas Organizações Globo. Para tanto, a pesquisa se consolida como um estudo de caso (YIN, 2015), a partir de uma pesquisa bibliográfica sobre fact-checking e onde também aborda obras de referência, periódicos científicos, teses e dissertações, anais científicos etc. (GIL, 2017). 
Para tanto, o presente estudo cita que o fact-checking nas Organizações Globo busca reforçar o conceito de credibilidade dos seus produtos de checagem, assim como a reformulação de um projeto editorial que ressalte o jornalismo profissional como antídoto contra a desinformação.

\section{Procedimentos metodológicos}

Tendo como suporte teórico a Economia Política da Comunicação (EPC), a pesquisa analisa criticamente as mudanças no processo de checagem de notícias nas redações das Organizações Globo, a partir de conceitos de Mosco (2016) e Andrade (2016). A Economia Política da Comunicação é denominada por Mosco (1999, p. 98) como o "[...] estudo das relações sociais, em especial das relações de poder, que constituem a produção, distribuição e consumo de recursos, incluindo os recursos da comunicação."

As pesquisas desenvolvidas na área investigam a introdução das novas tecnologias de comunicação e informação, além da transformação do trabalho, incluindo modelos e a natureza mutável na indústria de notícias. Nesse panorama, a Economia Política da Comunicação, em sua vertente crítica, estuda como as empresas vêm se adaptando às mudanças tecnológicas para mercantilizar seus conteúdos e serviços (ANDRADE, 2015). A partir dessa perspectiva, a EPC interpreta como os processos midiáticos são alterados diante da criação de novos produtos.

Caracterizada como um estudo de caso (YIN, 2015), a pesquisa investiga um fenômeno contemporâneo dentro de seu contexto em três polos cronológicos: pré-análise; exploração do material e tratamento dos resultados, incluindo a inferência e a interpretação (BARDIN, 1977). Justamente porque o estudo em questão coloca questões do tipo "como" e "por que" quanto à análise de processos organizacionais jornalísticos.

Para tanto, a realização dos procedimentos da pesquisa parte de uma análise do serviço de checagem "Fato ou Fake", que apresenta diretrizes de como os jornalistas do Grupo Globo devem apurar as informações. Partindo disso, a primeira fase da pesquisa inclui levantamento bibliográfico relacionado à apuração jornalística e fact-checking, além da coleta de dados nos sites em estudo e consulta em obras de referência, documentos na internet, periódicos científicos etc. 
Assim, esta pesquisa observa o uso do fact-checking no Grupo Globo como estratégia de garantia de credibilidade no mercado de notícias ${ }^{7}$. 0 conceito de estratégia não é analisado profundamente no estudo em questão, mas refere-se como uma "estratégia competitiva" dentro de um setor organizacional (MAGRETTA, 2018). 0 uso do termo em si está relacionado ao valor credibilidade para o jornalismo.

A renovação dos negócios se realiza por meio da busca de distinção em um mercado de concorrência, que encoraja os agentes a inovarem, adotando táticas que se afastam um pouco das regras tradicionais. Todavia, a verificação continua sendo uma prática fundamental para legitimar o papel de guardião do jornalismo.

\section{Fact-checking como aposta da credibilidade jornalística}

0 fact-checking é mais do que um gênero jornalístico, é uma prática de checagem de dados que questiona a veracidade das declarações públicas. 0 pesquisador norte-americano Lucas Graves (2013, p. 4, tradução das pesquisadoras) argumenta que os verificadores de fatos (fact-checkers) “[...] criaram uma espécie de notícia que responde - na verdade, que encena - crítica da prática da objetividade, que há muito tempo antecede a Internet, mas ganhou força com o advento de novas mídias".

Diante da perda de anunciantes e de assinaturas, os processos de verificação vêm sendo apregoados como garantia de notícias credíveis, principalmente por empresas que possuem seções ou editorias dedicadas à prática. No entanto, esses processos de verificação são cada vez mais questionados por políticos.

A luta pela sobrevivência na era da informação demonstra como os jornais estão aproveitando esse momento para reforçar suas qualidades de critério e credibilidade, apoiando-se muitas vezes na publicidade e na popularização de funcionais ferramentas de checagem. (SILVA, 2017, p. 13).

Canavilhas e Ferrari (2018) afirmam que conteúdo de qualidade custa muito dinheiro, mas os leitores estão mais preocupados com a veracidade das informações divulgadas nas redes sociais e por isso preferem confirmar e/ou ler dados publicados em veículos confiáveis. Palacios (2019) caracteriza a informação jornalística como uma

\footnotetext{
7 Charron e Bonville (2016) narram que Charles Frederick Hamilton (1879-1933) foi quem utilizou pela primeira vez a expressão mercant of news (mercado de notícias).
} 
mercadoria, ainda que de caráter simbólico, mas diferenciando-se por um elemento essencial: a credibilidade. "Sem tal ingrediente fundamental essa mercadoria tende a perder seu valor de mercado, [...] de qualquer empresa que se dedique a esse ramo de negócio e falhe em manter a credibilidade de seu produto" (PALACIOS, 2019, p. 78).

Mosco (2016) explana que a Economia Política do Jornalismo (EPJ) tende a concentrar-se mais no conteúdo da mídia e no trabalho envolvido na produção da mídia como no caso da checagem. "A ênfase em estruturas de mídia e conteúdo é compreensível à luz da importância das empresas de mídia globais e do crescimento do valor do conteúdo da mídia" (MOSC0, 2016, p. 51).

A indústria da informação tende a equilibrar entre o que é noticiável ou não, desde o processo de seleção, apuração até a distribuição. Para tanto, novos processos são instalados para satisfazer as expectativas do público, de assumir a rapidez da informação. Neste cenário hiperconcorrido, o fact-checking tem se configurado como uma aposta de mercado por empresas jornalísticas para promover a credibilidade de suas marcas. "Mais do que isso, a etapa de checagem bem realizada contribui para a construção de credibilidade acumulada pelo veículo de comunicação." (COSTA, 2019, p. 2).

No entanto, o mercado de checagem torna-se cada vez mais ocupado por entes externos (agências de checagem) a desempenhar uma função tão intrínseca à prática jornalística quanto a checagem de fatos. "O deslocamento do compromisso da checagem dos fatos expõe a fragilidade da mídia, uma vez que passou a existir no mercado jornalístico uma lacuna, ocupada pelas agências/serviços de fact-checking." (COSTA, 2019, p. 5).

Diante disso, empresas no país estão buscando encontrar estratégias para alinhar o conceito de credibilidade à prática de fact-checking. Para tanto, essas organizações midiáticas chegam a adotar práticas semelhantes às das agências de checagem, como etiquetas, selos e metodologias etc.

\section{Fact-checking no Grupo Globo: Diretrizes de checagem}

Uma das ferramentas utilizadas para nortear os jornalistas diante de suas fontes e das redes sociais é o Plano editorial das empresas em que trabalham. Esses documentos também abordam diretrizes quanto à checagem de fatos e os atributos que uma informação de qualidade deve ter. 
O Grupo Globo lançou em 2011 o documento Princípios Editoriais das Organizações Globo, atualmente intitulado Princípios Editoriais do Grupo Globo. 0 documento assinado por Roberto Irineu Marinho, João Roberto Marinho e José Roberto Marinho, que integram o Conselho do Grupo Globo, é orientado para todos os veículos que fazem parte da organização (Figura 1).

No documento, há um Preâmbulo Breve definição de jornalismo, que conta com três seções: (a) os atributos da informação de qualidade; (b) como o jornalista deve proceder diante das fontes, do público, dos colegas, do veículo para o qual trabalha e das redes sociais; (c) os valores cuja defesa é um imperativo do jornalismo.

Neste tópico, o documento aborda o conceito de verdade. Na visão do Grupo, o entendimento de que o jornalismo é a busca da verdade não passa de uma utopia, “[...] há técnicas que permitem ao público, na busca pelo conhecimento, minimizar a graus aceitáveis o subjetivismo." (PRINCÍPIOS EDITORAIS DO GRUPO GLOBO, 2011, online).

Ainda no documento, o Grupo ressalta que o jornalismo produz conhecimento, o mesmo que dizer que busca a verdade dos fatos. Em outro parágrafo, é interessante observar o posicionamento do Grupo sobre o que é fazer propaganda ou jornalismo. Neste trecho fica evidente a intenção da organização em se autoafirmar credível diante dos veículos concorrentes no mercado.

O veículo cujo objetivo central seja convencer, atrair adeptos, defender uma causa, faz propaganda. Um está na órbita do conhecimento; o outro, da luta político-ideológica. Um jornal de um partido político, por exemplo, não deixa de ser um jornal, mas não pratica jornalismo, não como aqui definido: noticia os fatos, analisa-os, opina, mas sempre por um prisma, sempre com um viés, o viés do partido. E sempre com um propósito: o de conquistar seguidores. Faz propaganda. Algo bem diverso de um jornal generalista de informação: este noticia os fatos, analisa-os, opina, mas com a intenção consciente de não ter um viés, de tentar traduzir a realidade, no limite das possibilidades, livre de prismas. Produz conhecimento. 0 Grupo Globo terá sempre e apenas veículos cujo propósito seja conhecer, produzir conhecimento, informar. (PRINCÍPIOS EDITORAIS DO GRUPO GLOBO, 2011, online).

Na seção I Os atributos da informação de qualidade, o documento aborda três princípios básicos do trabalho jornalístico: isenção, correção e agilidade. No tópico A isenção, o documento destaca que quanto à apuração, edição e publicação de uma reportagem, seja ela factual ou analítica, os diversos ângulos que cercam os acontecimentos que ela busca retratar ou analisar devem ser abordados. 
Na seção II Como o jornalista deve proceder diante das fontes, do público, dos colegas, do veículo para o qual trabalha e das redes sociais, o documento orienta que as informações e imagens enviadas pelo público por meio da internet apenas devem ser publicadas depois de averiguação (PRINCÍPIOS EDITORAIS DO GRUPO GLOBO, 2011, online).

Figura 1 - Essência Globo

GRUPCSLOBO

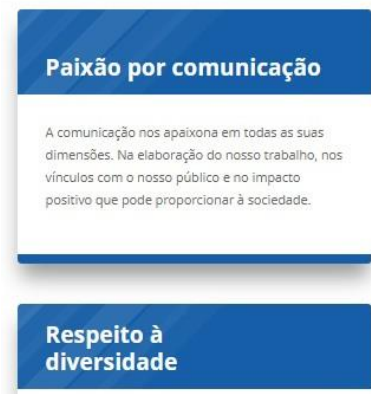

Orespeito ao outro, a valiorização da diversiddade e a convicção de que todos dependem de todos sà componentes essenciais da nossa identidade.

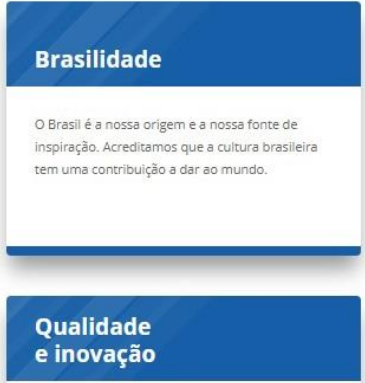

Buscamos qualidade em tudo $\circ$ que fazemos. Queremos que nosso púbilico perceba nossos produtos como os melhores, os mais criativos mais inovadores

Fonte: Essência Globo (2018), Imagem de captura de tela da editoria.

Dentre os tópicos abordados dentro da seção, o documento grifa que os jornalistas do mesmo veículo devem cooperar entre sim. "Os envolvidos numa mesma reportagem - da apuração à edição - são responsáveis por sua qualidade. Devem agir como revisores uns dos outros, para bem do trabalho" (PRINCÍPIOS EDITORAIS DO GRUPO GLOBO, 2011, online). Enquanto na seção III Os valores cuja defesa é um imperativo do jornalismo, o Grupo Globo ressalta que sempre será independente, apartidário, laico e praticará um jornalismo que busque a isenção, a correção e a agilidade. Em outro documento Visão, Princípios e Valores, de 1997, a organização defende valores e princípios que garantem os bons resultados dos seus negócios.

Com o Fato ou Fake, a Globo ressalta que o serviço de checagem é destinado a apurar fatos comprováveis (Figura 2), excluindo opiniões e dados lastreados em observações de tendências ou previsão de acontecimentos futuros. Os jornalistas são orientados a monitorar as redes sociais por meio de ferramentas sobre o resultado do monitoramento e das checagens. Tais orientações são com base no Projeto Editorial das Organizações Globo $(G 1,2018)$. 
Para Guerra (2014), existem dois modos convencionais usados por organizações jornalísticas para justificar sua credibilidade: o primeiro, o histórico de bons serviços prestados à comunidade; o segundo, a audiência cativa e em quantidade que por si seria uma demonstração suficiente da credibilidade usufruída.

A credibilidade resulta de uma série de informações capazes de atestar sua idoneidade. "A credibilidade editorial para se validar por meios técnicos e científicos requer a transparência em relação às informações necessárias para a aferição tanto da credibilidade organizacional quanto da credibilidade do conteúdo" (GUERRA, 2014, p. 205).

Figura 2 - Declaração de Jair Bolsonaro ao Jornal Nacional

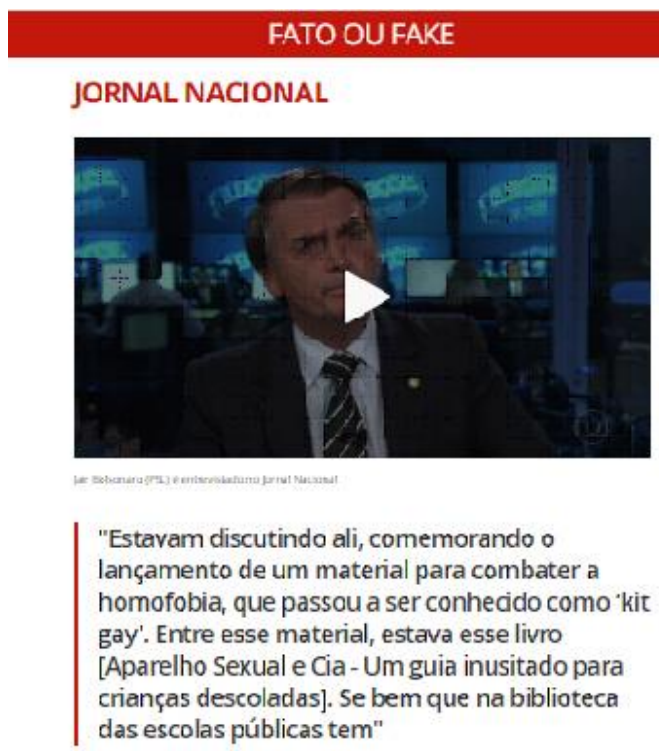

\section{FAKE}

Fonte: G1 (2018).

Assim fica claro que o projeto editorial do Grupo Globo busca garantir uma transparência necessária à sustentação da sua credibilidade no mercado, embora o autor supracitado ressalte que a credibilidade de uma organização está muitas vezes encoberta por obscuridades que não permitem avaliar criteriosamente a existência de fatores objetivos capazes de demonstrar tal compromisso.

Convém acrescentar que nas eleições de 2018, os jornalistas do Grupo Globo foram alvos de críticas do presidente Jair Bolsonaro e de seus seguidores, inclusive de difamações do atual presidente após a exibição de apurações de suas declarações e condutas. Diante 
dessas críticas, 0 Grupo Globo se posicionou na defesa da liberdade de informação, com base nos códigos deontológicos da profissão e das diretrizes do seu plano editorial.

\section{Fato ou Fake: checagem colaborativa do Grupo Globo na defesa da credibilidade jornalística}

Antes do lançamento do Fato ou Fake, o Portal G1 lançou uma campanha de divulgação em TV, rádio e jornal com o título "Duvide". Um dos vídeos de divulgação resume as intenções do projeto: "O bom jornalismo nasce da dúvida. Se aconteceu, é fato. Se é mentira, é fake. Só que hoje em dia é muito difícil separar o fato do fake. [...] E conferindo a gente descobre o que de fato é fato e o que de fato é fake [...]" (G1, 2018, online).

0 jornalista deve trabalhar no processo de seleção, preparação e hierarquização das notícias. Pois, a notícia é a representação social dos fatos e gerada numa instituição que pressupõe uma complexa organização. "Mas, além disso, o papel da mídia é institucionalizado e tem a legitimidade de gerar a realidade socialmente relevante." (ALSINA, 2009, p. 14).

A metodologia de fact-checking do Grupo mescla ferramentas e dados entre os veículos. Por exemplo: Quando uma informação divulgada nas redes sociais é suspeita, os jornalistas investigam a fonte que deu origem a ela assim como outros pontos. A apuração também aborda fontes oficiais, testemunhas e especialistas que possam ajudar a esclarecer o que está escrito ou dito no conteúdo. Para o Grupo Globo, o principal critério de checagem é a transparência de informações (Quadro 1), baseada em três pilares:

Os veículos que atuam no serviço de checagem Fato ou Fake trabalham com três selos, espécies de etiquetas bastante usadas por verificadores: Fato (quando o conteúdo checado é totalmente verídico e comprovado por meio de dados e fontes); Não é bem assim (quando é parcialmente verdadeiro, exagerado ou incompleto); Fake (quando não se baseia em fatos comprovados por meio de dados, datas, locais, fontes oficiais e especialistas. 
Quadro 1 - Pilares de transparência do Grupo Globo

\begin{tabular}{l} 
Transparência de fontes - o objetivo é que o leitor veja com clareza o caminho de apuração \\
percorrido pelo jornalista. Para isso, todas as fontes consultadas durante a checagem estarão \\
identificadas no texto, sejam elas pessoas ou instituições. \\
\hline Transparência de metodologia - o processo de seleção da mensagem a ser checada, a apuração e a \\
classificação da checagem são claras, deixando em destaque o que levou a informação a ser checada, \\
como ocorreu a apuração e o motivo da classificação como fato ou fake. \\
Transparência de correções - caso haja alguma modificação na checagem que tenha comprometido \\
a sua publicação original, essa alteração estará devidamente identificada na reportagem.
\end{tabular}

Fonte: Portal G1 (2018).

As checagens colaborativas nas Organizações Globo também contam com o apoio de um "bot" (robô) no Facebook e no Twitter para classificar o que é falso ou verdadeiro, caso o assunto já tenha sido verificado pelas equipes. Por meio de um número de WhatsApp8, os usuários cadastrados também podem visualizar os links das checagens realizadas.

A construção de equipes multidisciplinares corrobora para que os veículos lidem melhor com a grande quantidade de informações disponíveis nos ambientes virtuais. Essas equipes também contam com apoio de profissionais com perfis mais técnicos, como programadores de computador. "Graças a essas colaborações, é possível o desenvolvimento de ferramentas e algoritmos que permitam verificar um grande volume de informações e dados em menor tempo e com maior confiabilidade" (VIZOSO; LÓPEZ-GARCÍA; PEREIRAFARIÑA, 2018, p.120, tradução das pesquisadoras).

Em um vídeo datado de 29 de julho de 2019, o Portal G1 exibiu dados de 1.155 checagens realizadas em um ano após a implantação do Fato ou Fake. Com o slogan "É jornalismo para o fake não virar news", o vídeo apresenta as equipes de fact-checking que integram o Núcleo de Jornalismo de Dados e Checagem. Além da editoria, o portal G1 conta com um Banco de Boatos, onde é feita a verificação das mensagens que viralizam nas redes sociais e as classificam em fatos ou fakes. Enquanto os outros veículos do Grupo apenas exibem a editora Fato ou Fake. 
Figura 3 - Fato ou Fake na Revista Valor Econômico

\begin{tabular}{l|l|l|l|l|l} 
Q. Buscar & Valor & Fato ou Fake Er
\end{tabular}

\section{E \#FAKE print do Telegram admitindo alteração de textos por hackers}

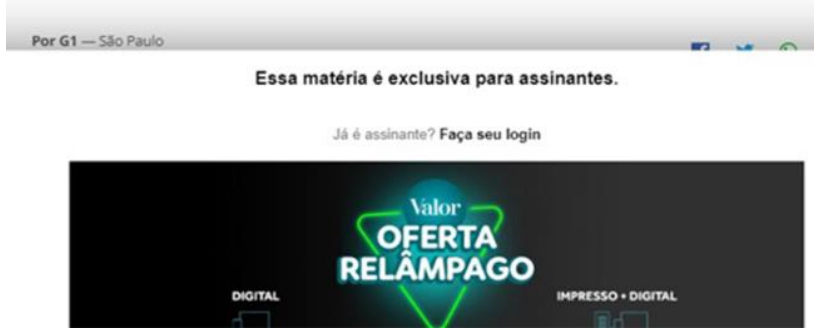

Fonte: revista Valor Econômico (2019).

É notório que as empresas buscam novas metodologias de checagem. Mosco (2016) ressalta que o mercado de comunicação integra uma cadeia de produtores tais como uma empresa jornalística, distribuidores impressos e online, para finalmente alcançar os leitores, cujas aquisições e atenção retroalimentam novos processos de produção.

As transformações que vêm ocorrendo nas redações com a implantação do factchecking acontecem num contexto de reconfiguração do capitalismo avançado, que evidencia a concentração e a mercantilização de processos e práticas de checagem na garantia de notícias credíveis para os usuários. "A preocupação com expansão e rentabilidade leva ao ponto onde ganha relevância a produção de conteúdos que se revelem economicamente rentáveis." (ANDRADE, 2016, p. 150).

Convém acrescentar que o Portal G1 não integra nenhum projeto colaborativo de checagem independente, apenas participa de ações de checagem promovidas pelas Organizações Globo. O G1, Época, Extra, O Globo (versão digital do jornal O Globo) e o GloboNews (portal do canal de televisão por assinatura) não limitam a visualização das checagens para o público. Embora as checagens da editoria também sejam compartilhadas na Revista Valor Econômico, elas são apenas visualizadas por assinantes (Figura 3), sendo que o veículo consta apenas com checagens divulgadas até o dia 30 de julho de 2019. 


\section{Considerações finais}

Grupos empresariais vêm criando produtos e estratégias no mercado brasileiro diante da perda de anunciantes e assinaturas. Com uma editoria exclusiva de fact-checking, o portal G1 compartilha suas checagens com os veículos que fazem parte das Organizações Globo, inclusive com o Jornal Nacional e a GloboNews. Embora não disponibilize assinaturas digitais, o portal possui apenas conteúdo gratuito e ilimitado para todos que o acessam. Nesse contexto, há a necessidade das organizações midiáticas em oferecer conteúdos exclusivos e de credibilidade.

No entanto, a Revista Valor Econômico utiliza a editoria Fato ou Fake para atrair mais assinantes, pois quando há a tentativa de acessar a editoria para visualizar as verificações, o veículo informa que é exclusivo para assinantes, conforme apurado neste estudo. Isso se consolida como uma estratégia que a própria Economia Política da Comunicação (EPC) evidencia.

No mercado atual, com a ascensão das agências de checagem há também por outro lado, o fortalecimento dentro das organizações jornalísticas da checagem "[...] como parte essencial do processo de criação da narrativa jornalística, enquanto um formato discursivo diferenciado, e da garantia da sua credibilidade" (PALACIOS, 2019, p. 88).

Embora ofact-checking seja anunciado como garantia de credibilidade, esta pesquisa destaca que a transparência é essencial e ajuda a deixar bem claro que o jornalista tem um motivo ou interesse público. Assim, o Grupo Globo precisa trabalhar melhor a transparência dessas ferramentas de checagem colaborativa para o público. Pois, em tempos de audiências cada vez mais fragmentadas há uma disputa acirrada por quem entrega conteúdo de qualidade e confiável no mercado.

\section{Referências}

ALSINA, M. R. A construção da notícia. Petrópolis: Vozes, 2009.

ANDRADE, S. Jornalismo em mutação: estudo sobre a produção de conteúdo na fase do capitalismo avançado. Teresina: EDUFPI, 2015.

ANDRADE, S. Que jornalismo é esse? A produção de jornalismo na fase das indústrias culturais. In: DOURADO, J. L.; LOPES, D. M. M. S; MARQUES, R. S. (org.). Economia política 
do jornalismo: tendências, perspectivas e desenvolvimento regional. Teresina: EDUFPI, 2016. p. 117-147.

BARDIN, L. Análise de conteúdo. Lisboa: Edições 70, 1977.

CANAVILHAS, J.; FERRARI, P. Fact-checking: o jornalismo regressa às origens. In: BUITONI, D. Jornalismo em tempo de transformação: desafios de produção e de ação. Porto Alegre: Sulina, 2018. p. 30-49.

CHARRON, J.; BONVILLE, J. 0 jornalismo e o mercado: da concorrência à hiperconcorrência. In: CHARRON, J.; BONVILLE, J. (ed.). Natureza e transformação do jornalismo. Florianópolis: Insular; Brasília: FAC Livros, 2016. cap. 7, p. 337-385.

COSTA, A. C. Credibilidade e jornalismo: "fact-checking" e as mudanças no mercado de notícias brasileiro. In: CONGRESSO BRASILEIRO DE CIÊNCIAS DA COMUNICAÇÃO, 42., 2019, Belém. Trabalhos[...]. Belém: Universidade Federal do Pará, 2019.

EDELMAN. 2020 Edelman Trust Barometer. New York, 2020.

G1. Princípios editoriais do Grupo Globo. Rio de Janeiro, 2011.

G1. G1 lança Fato ou Fake, novo serviço de checagem de conteúdos suspeitos. Rio de Janeiro, 2018.

G1. Veja o que é \#FATO ou \#FAKE nas entrevistas de Jair Bolsonaro para o Jornal Nacional e para o Jornal das Dez. Rio de Janeiro, 2018.

GIL, Antônio Carlos. Como elaborar projetos de pesquisa. 6. ed. São Paulo: Atlas, 2017.

GRAVES, L. Deciding what's true: the rise of political fact-checking in american journalism. 2013. Thesis. (Doctor of Philosophy)-Graduate School of Arts and Sciences, Columbia University, New York, 2013.

GRUPO GLOBO. Essência Globo. Rio de Janeiro, 2011. Disponível em: https://grupoglobo.globo.com/. Acesso em: 7 de jan. 2020.

GUERRA, J. L. Transparência editorial: a credibilidade jornalística à luz dos sistemas de gestão da qualidade. Revista Latinoamericana de Ciencias de la Comunicación, v. 11, n.20, p.196-209, 2014

MAGRETTA, J. Entendendo Michael Porter: o guia essencial da competição estratégia. Tradução Carlos Szlak. Rio de Janeiro: Alta Books, 2018.

MOSCO, V. Economia Política do Jornalismo. In: DOURADO, J. L.; LOPES, D. M. M. S.; MARQUES, R. S. (org.). Economia política do jornalismo: tendências, perspectivas e desenvolvimento regional. Teresina: EDUFPI, 2016. p. 43-67. 
MOSCO, Vincent. Economia política da comunicação: uma perspectiva laboral. Comunicação e sociedade 1 - Cadernos do Nordeste, Braga, v. 12, n. 1-2, p. 97-120, 1999.

PALACIOS, M. Fake news e a emergência das agências de checagem: terceirização da credibilidade jornalística?. In: MARTINS, M.; MACEDO, I. (ed.). Políticas da língua, da comunicação e da cultura no espaço lusófono. Vila Nova de Famalicão: Edições Humus, 2019. p. 77-92.

PROJETO COMPROVA. Sobre o Comprova. [S. l.], 2018.

SEIBT, T. Jornalismo de verificação como tipo ideal: a prática de fact-checking no Brasil. 2019. Tese (Doutorado em Comunicação)- Faculdade de Biblioteconomia e Comunicação, Universidade Federal do Rio Grande do Sul, Porto Alegre, 2019.

SILVA, N. M. R. Fake news: a revitalização do jornal e os efeitos fact-checking e crosscheck no noticiário digital. Temática, João Pessoa, v. 13, n. 8, p. 12-29, ago. 2017.

STENCEL, M; LUTHER, J. Fact-checking census shows slower growth. [S. l.], 2021.

Disponível em: https://reporterslab.org/fact-checking-census-shows-slower-growth/. Acesso em: 26 de jul. 2021.

URETA, A. Convergência e transformação estrutural dos meios de comunicação na Europa: oportunidades e riscos diante da crise do modelo de negócio tradicional. Tradução Juliana Fernandes Teixeira. In: DOURADO, J. L.; LOPES, D. M. M. S; MARQUES, R. S. (org.). Economia política do jornalismo: tendências, perspectivas e desenvolvimento regional. Teresina: EDUFPI, 2016. p. 93-116.

VALOR. É \#FAKE print do Telegram admitindo alteração de textos por hackers. São Paulo, 2019.

VIZOSO, A.; LÓPEZ-GARCÍA, X.; PEREIRA-FARIÑA, X. Habilidades tecnológicas como factor clave en el perfil del fact checker para la verificación de la información en la sociedad red.

Estudos em Comunicação, Covilhã, n. 27, v. 1, p. 105-126, dez. 2018.

YIN, Robert. Estudo de caso: planejamento e métodos. 3. ed. Porto Alegre: Bookman, 2015.

Credibility at stake: the use of fact-checking in the G1 portal and collaborative checking in Globo Organizations

\footnotetext{
Abstract

This article analyzes the collaborative checking of Fato ou Fake, Grupo Globo's content monitoring and checking service. Therefore, the work carries out a case study based on the guidelines contained in the Editorial Plan of the Group and in the
} 
Fact or Fake section of the G1 Portal, which point to factchecking as a credibility strategy.

\section{Keywords}

Fact-checking; Credibility; Political Economy of Communication

\section{Autoria para correspondência}

Marta Thaís Alencar

martaalencarpi@outlook.com

\section{Como citar}

COSME, Martha Thaís Alencar; DOURADO, Jacqueline Lima. Credibilidade em jogo: o uso do fact-checking no portal G1 e a checagem colaborativa nas Organizações Globo. Intexto, Porto Alegre, n.53, e-101015 jan./dez. 2022. DOI: http://dx.doi.org/10.19132/1807-8583202253.117417

Recebido em 12/03/2020

Aceito em 17/08/2021 